\title{
Fractality in Manufacturing Industry
}

\author{
Miguel Montaño-Alvarez ${ }^{1}$, Marcos Salazar-Medina² ${ }^{2}$ Tomás Morales-Acoltzi ${ }^{3}$, Leydi Guzmán-Aguilar ${ }^{1}$, Ángel $^{2}$ \\ Machorro-Rodríguez ${ }^{2} \&$ Edna Araceli Romero-Flores ${ }^{2}$ \\ ${ }^{1}$ Masters in Administrative Engineering, Tecnológico Nacional de México, Instituto Tecnológico de Orizaba, Ver. \\ Oriente 9 No. 852 Colonia Emiliano Zapata, México \\ ${ }^{2}$ División de Estudios de Posgrado e Investigación, Tecnológico Nacional de México, Instituto Tecnológico de \\ Orizaba, Ver. Oriente 9 No. 852 Colonia Emiliano Zapata, México \\ ${ }^{3}$ Centro de Ciencias de la Atmósfera (Center for Atmospheric Sciences), UNAM, Circuito exterior, CU, CDMX, \\ México \\ Correspondence: Miguel Montaño-Alvarez, Masters in Administrative Engineering, Tecnológico Nacional de \\ México, Instituto Tecnológico de Orizaba, Ver. Oriente 9 No. 852 Colonia Emiliano Zapata, C.P. 94320, México.
}

Received: November 22, 2016

doi:10.5430/ijba.v8n1p65
Accepted: December 7, $2016 \quad$ Online Published: January 10, 2017

URL: http://dx.doi.org/10.5430/ijba.v8n1p65

\begin{abstract}
Fractal theory, a topic first introduced by Mandelbrot in 1970, has nevertheless witnessed a great boom in the field of science in this last decade. In this article, we analyze time series (TS), behavior of the variable, cost of that sold (CS), and we assume and demonstrate that there is fractality in the system for manufacturing companies in Mexico. We analyzed 30 companies that are listed on the Mexican stock exchange, obtaining 23 data for each organization, taking a period stretching from the first quarter of 2010 to the third quarter of 2015, and obtaining a total of 704 data. We only selected 512 for each one of the 30 TS, using fractal interpolation (FI) as the method for generating data in TS. TS 30 was characterized from the point of view of Visual Recurrence Analysis (VRA) software. It is apparent that in $80 \%$ of the companies analyzed, the dynamics of the CS system were elucidated using 4 variables.
\end{abstract}

Keywords: fractal, fractality, cost of that sold, manufacturing companies, system dynamic, fractal interpolation

\section{Introduction}

In 1970, Benoit Mandelbrot of Polish origin proposed the fractal theory and was considered the pioneer of these studies. He defined them as "a set of forms which are normally generated by a process of repetition, characteristically have detail at all scales. This is due to their infinite length, the fact they are not differentiable and because they exhibit the fractional dimension" (Mandelbrot, 1982). A more simplified definition is that proposed by Garnett (Williams, 1997), defining them as "A line, surface or pattern that looks the same on a wide range of scales." Up to now, different studies have been generated with a fractal approach in various disciplines, for example studies and modeling of the internal geomagnetic field (O.A. Khachay, A.Yu. Khachay, \& O.Yu. Khachay, 2012); Competence systems from the perspective of business competition (Deng, Peng, \& Huang, 2009); Cerebral magnetic resonance angiography (De la Rosa-Orea et al., 2014); among others, such as art, music, etc. In the manufacturing context, some contributions include the modeling and specification of dynamic agents in fractal manufacturing systems (Ryu, Son, \& Jung, 2003); models for optimizing the logistic financial management system (Wang, Luo, \& Peng, 2008); fractal company (Gálvez, Balankin, \& Resenos, 2009); Inventory management in supply chain networks (Ryu, Moon, Oh, \& Jung, 2013); Sustainable fractal manufacturing in mechanized processes (Peralta, Marcos, Aguayo, Lama, \& Córdoba, 2015). The objective of this research is to analyze whether fractality exists in the CS variable, as a subsystem that impacts the production area of a manufacturing company. The second section presents the database (DB); and in the third section we describe the methodology. The fourth section presents numerical experiments and results; and finally, the conclusions are in section five.

\section{Base de Datos}

The manufacturing context is a space where the productive processes of processing or transformation of one or several raw materials are concentrated, which through different mechanisms, enable the addition of value to the final product. The production managers in a manufacturing plant, seek to maintain their processes within established 
limits, in order that the final result has acceptable characteristics for commercialization, however, there are a number of variables that affect the behavior of these processes.

The variable to be analyzed is the $\mathbf{C S}$, which is manifested in the production area and mainly consists of the sum of labor costs, raw materials, energy, depreciation, and maintenance, among others. In the capital series section, 145 companies that were listed on the Mexican Stock Exchange were found (MSE) (MSE Group, 2016), of which, the following were selected:

- $\mathrm{CH}$

- TENARIS

- AUTLAN

- AHMSA

- COLLADO

- SIMEC

- BIMBO

- HERDEZ

- ALFA

- baFAR
CERAMIC

GRUMA

BACHOCO

CONVERTIDORA

CEMEX

HILASAL

COCACOLA

MINSA

AC

CULTIBA
ELEMENT

KIMBERLY

LAMOSA

MASECA

NEMAK

PAPPEL

VASCONI

VITRO

POCHTEC

RASSINI

\section{Methodology}

To obtain the information, the 145 companies consulted in the MSE were stratified, selecting those involved in manufacturing activities, resulting in 41 companies, of which, 30 were considered to meet with specifications of: availability of information and time period (First quarter of 2010 to the third quarter of 2015).

The methodology of dynamic nonlinear systems, requires at least 512 data, in the consulted DB, 23 registers are available for each TS. To meet this requirement, four methods were analyzed; random numbers generated by their distribution, arithmetic mean, geometric mean, and FI. To maintain dynamic characteristics, we consider that fractal interpolation is the best method.

FI (Barnsley, 1988) makes it possible to generate data from a series of points, while maintaining the original behavior of the system. The general equation is:

$$
w_{n}\left(\begin{array}{l}
x \\
y
\end{array}\right)=\left(\begin{array}{cc}
a_{n} & 0 \\
c_{n} & d_{n}
\end{array}\right)\left(\begin{array}{l}
x \\
y
\end{array}\right)+\left(\begin{array}{l}
e_{n} \\
f_{n}
\end{array}\right)
$$

To calculate the parameters of the general equation, we obtained these from the following equations:

$$
\begin{gathered}
a_{n}=\frac{x_{n}-x_{n-1}}{x_{N}-x_{0}} \\
e_{n}=\frac{\left(x_{N} x_{n-1}-x_{N} x_{0}\right)}{x_{N}-x_{0}} \\
c_{n}=\frac{\left(F_{n}-F_{n-1}\right) /\left(x_{N}-x_{0}\right)-d_{n}\left(F_{N}-F_{0}\right)}{x_{N}-x_{0}} \\
f_{n}=\frac{\left(x_{N} F_{n-1}-x_{0} F_{n}\right)}{\left(x_{N}-x_{0}\right)}-d\left(\frac{\left(x_{N} F_{0}-x_{0} F_{N}\right)}{\left(x_{N}-x_{0}\right)}\right)
\end{gathered}
$$

Where:

$d_{n}$ Represents a factor of vertical scale, which can be any real number.

$a, c, e, f$ Are real numbers, this is known as a transformation to the order of two dimensions.

To treat the data, three factors on the scale of $(0,1]$ are required, for the FI undertaken in this work, we used $0.5,-0.5$ and 0.23 , respectively.

To determine the degree of fractality of TS, VRA software was used (Kononov, 1996), which provided us with the information: Optimal flow and correlation dimension. 


\section{Results and Discussion}

TSs were submitted to two tests, arithmetic mean and geometric mean, respectively, in order to verify that they had not been manipulated. These tests were performed for the 30 companies to exemplify these operations; the analysis of the $\mathrm{CH}$ company is partially presented in Tabl.

Table 1. Analysis of components of the $\mathrm{CH}$ company system, by arithmetic mean and geometric mean

\begin{tabular}{ccc}
\hline & \multicolumn{1}{c}{ CH company } & \\
\hline Data & Arithmetic mean & Geometric mean \\
\hline $\mathbf{5 7 6 1 0 6 4}$ & & \\
$\mathbf{5 9 8 7 6 3 0}$ & 5866017.5 & 5865078.522 \\
$\mathbf{5 9 7 0 9 7 1}$ & 4398815.5 & 4101858.882 \\
$\mathbf{2 8 1 0 0 0 1}$ & 6101192.5 & 6099802.643 \\
$\mathbf{6 2 3 1 4 1 4}$ & 4905579.5 & 4435454.991 \\
$\mathbf{7 0 0 1 1 5 8}$ & 6886807 & 6855550.355 \\
$\mathbf{7 5 4 2 2 0 0}$ & 7170166.5 & 7168174.368 \\
\hline
\end{tabular}

The original information presents dissimilar amounts between each TS, for example, a company with CS of \$ 135 14913.00, and another with CS of $\$ 25879.00$. For this reason, it was necessary to normalize the information, dividing each data in the series by its maximum value, thus obtaining a point of comparison between the different companies.

After normalizing TS, the original TSs were graphically compared with standardized TSs to verify that behavior had not been affected by their properties. Figure 1 and Figure 2 show that behavior is identical in both graphs.

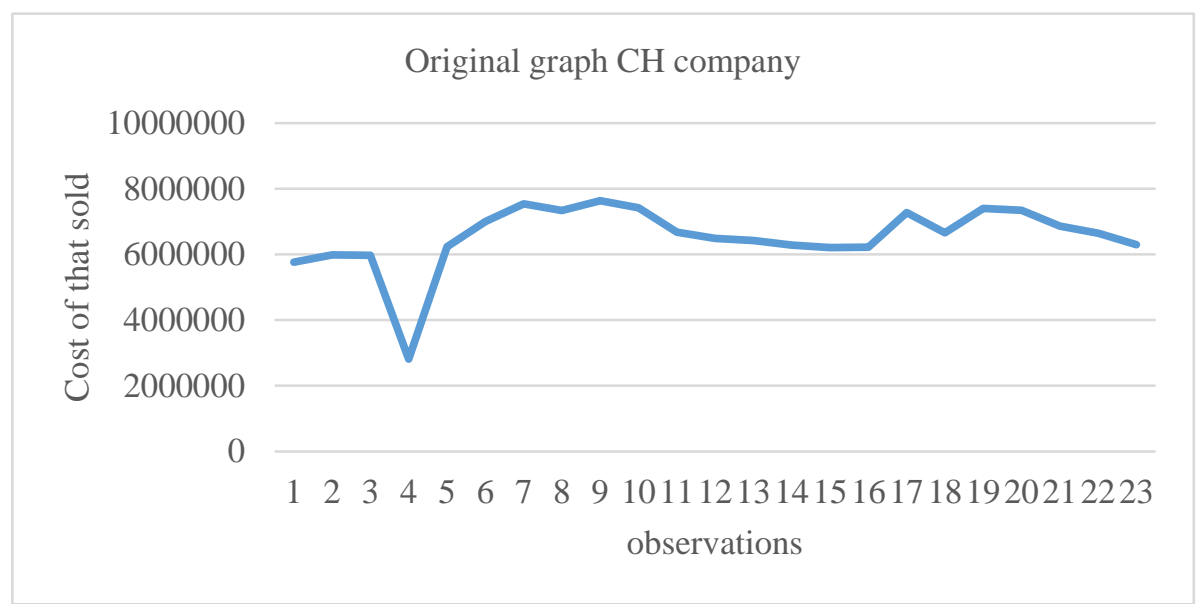

Figure 1. Graph of the cost of that sold by the $\mathrm{CH}$ company 


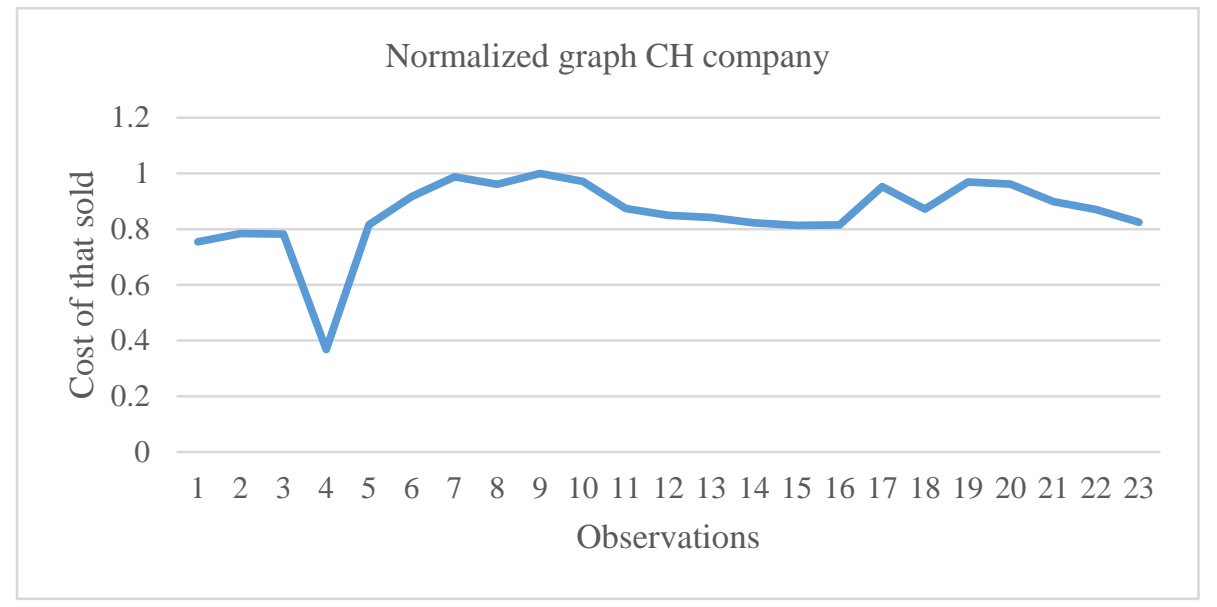

Figure 2. Graph of the cost of that sold after being normalized

We used VRA software to determine whether there is fractality in TS, making it necessary to generate information through the available data, proposing four options:

1) To generate random numbers by their distribution.

2) To generate data by their arithmetic mean.

3) To generate data by their geometric mean.

4) To generate data by fractal interpolation.

The first option determines which distribution is adjusted by the TS (Figure 3), considering 3 parameters: Graph, P-value and Anderson-Darling (AD), the distributions with lower AD were chosen and hypothesized with alpha 0.05. The values for $\mathbf{C S}$ were found to be $\mathrm{P}(0.124)>0.05, \mathrm{AD}=0.586 ; \mathrm{P}(0.124)>0.05, \mathbf{A D}=0.586$; therefore, TS belongs to a smaller end value type distribution.

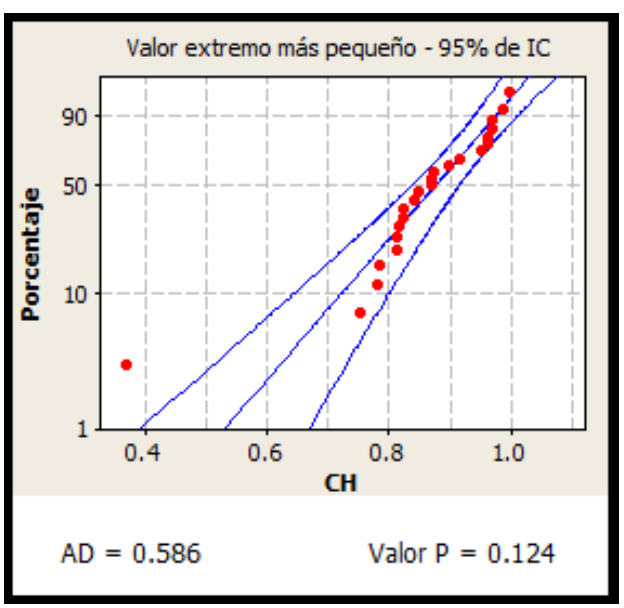

Figure 3. The graphic behavior for the cost of that sold by the $\mathrm{CH}$ companies and the $\mathrm{P}$ and $\mathrm{AD}$ tests

After determining the distribution to which TS belongs, five hundred and twelve random numbers were generated in Minitab, while maintaining the distribution of the original TS (Figure 4). 


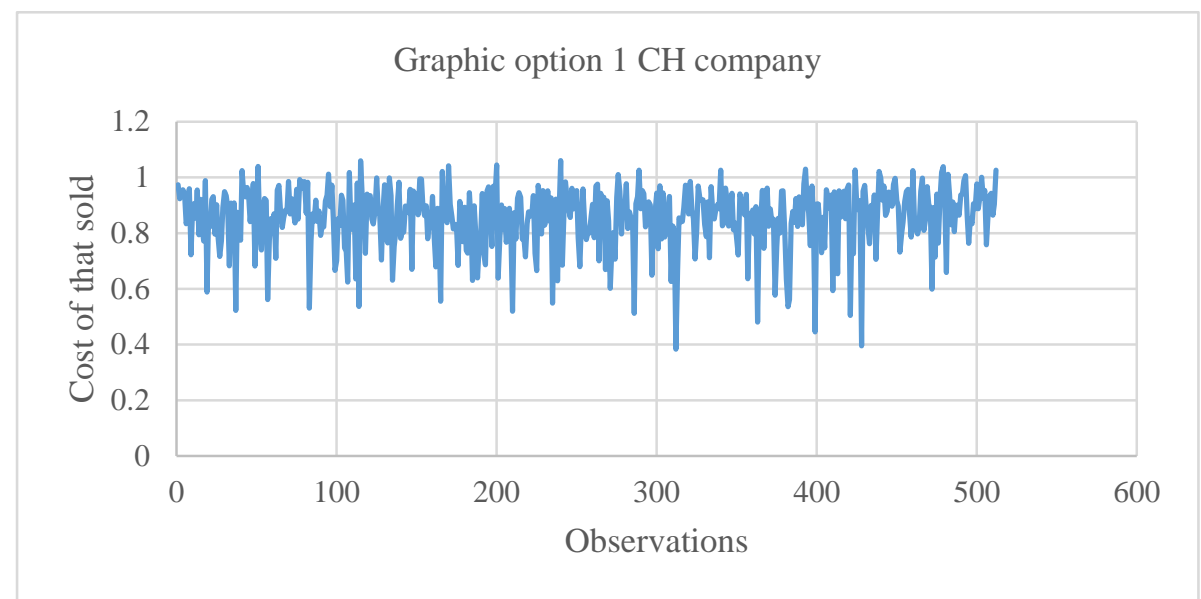

Figure 4. Graph of the numbers generated by the distribution system of the $\mathrm{CH}$ company

Although data were generated from the analysis of the original information, the new TS does not maintain the same pattern of behavior, so it is considered that this is not an adequate option with which to complete the required number of the sample.

The second option shows the generation of data by the arithmetic mean, and Figure 5 shows that the points obtained are positioned on the line of the original TS.

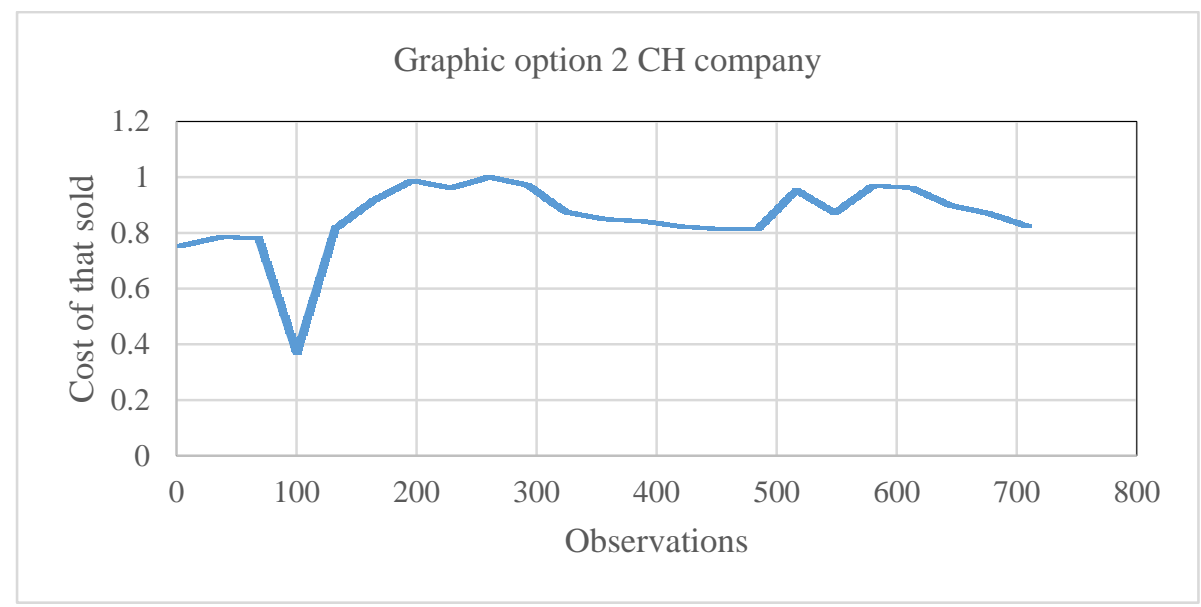

Figure 5. Graphic data for numbers generated by arithmetic mean for the $\mathrm{CH}$ company

The third option generates data using the geometric mean, showing that they maintain the same shape as the original TS (Figure 6), with the peculiarity that when plotting both options, the data tend to adjust to a straight line. 


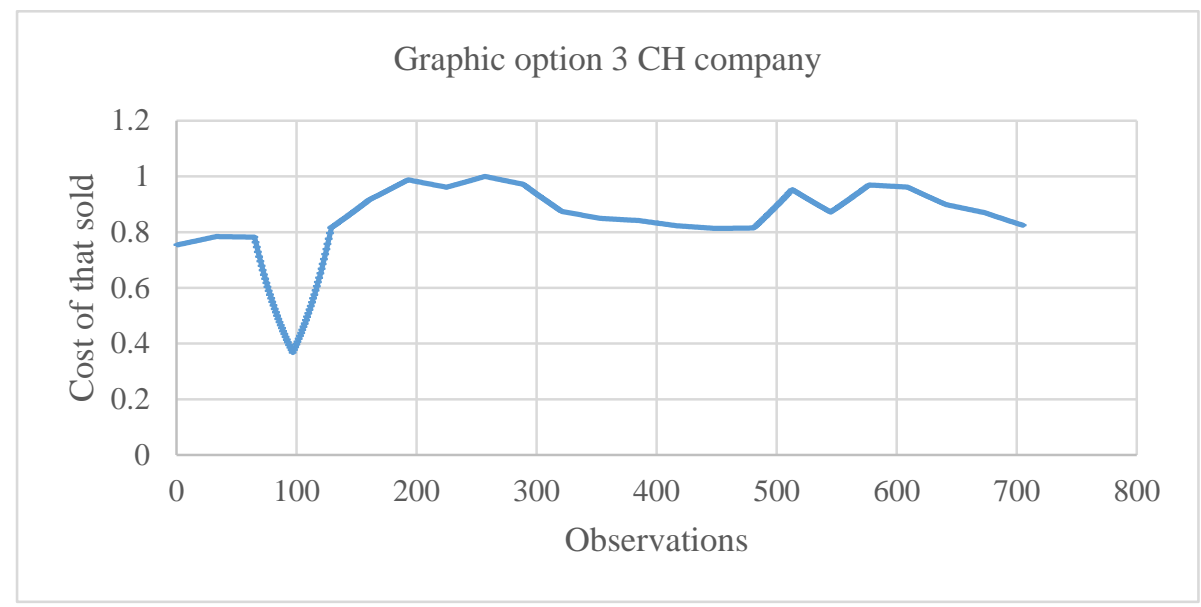

Figure 6 . The graph generated by creating data using the geometric mean

The fourth option refers to fractal interpolation, observing that the data obtained manifest the same behavior as the original TS (Figure 7).

After reviewing the above options, we decided to use fractal interpolation.

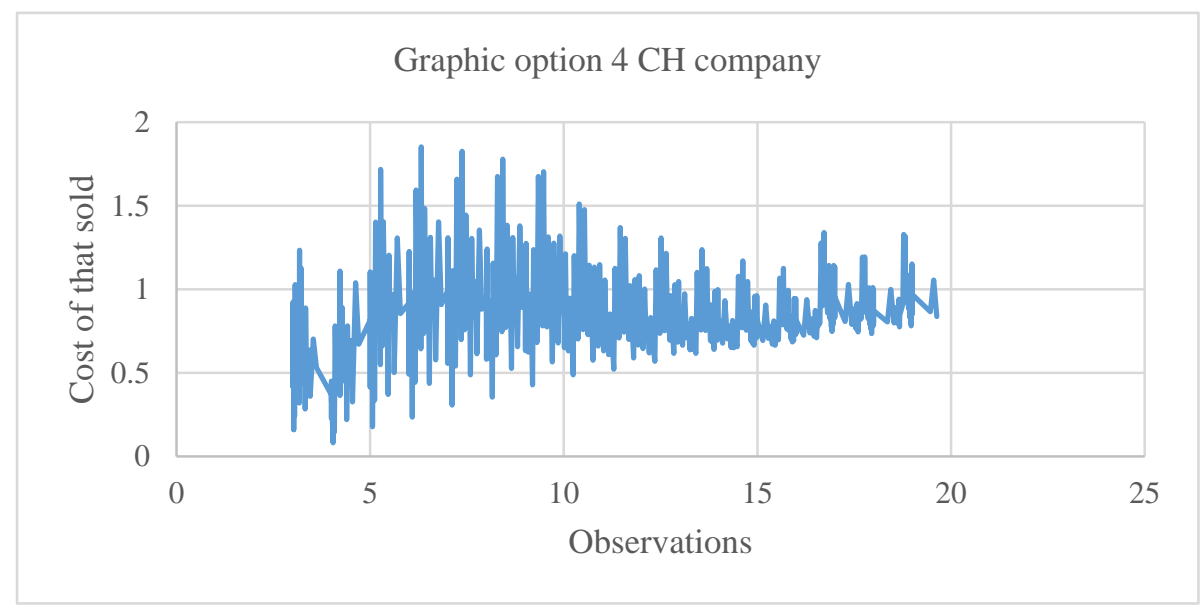

Figure 7. The behavior of the data created using fractal interpolation of the $\mathrm{CH}$ company

We performed the FIs of the companies being studied and with the information obtained and using the VRA, we obtained the Tao $(\boldsymbol{\tau})$, which is the value that indicates the sensitivity of TS. Other data provided is the correlation dimension (D), which shows the point of convergence, and also provides information about the number of variables, which can explain the system and from which Table 2 is constructed. 
Table 2. Results from the analysis using VRA, which prove that manufacturing companies manifest fractal behavior

\begin{tabular}{llllll}
\hline COMPANY & $\boldsymbol{\tau}$ & $\mathbf{D}$ & COMPANY & $\boldsymbol{\tau}$ & D \\
\hline AUTLAN & 1 & 3.67 & MASECA & 3 & 3.29 \\
BAFAR & 1 & 3.62 & BIMBO & 1 & 3.25 \\
CONVERTIDORA & 3 & 3.62 & BACHOCO & 1 & 3.24 \\
RASSINI & 1 & 3.58 & ALFA & 3 & 3.21 \\
HILASAL & 3 & 3.47 & POCHTEC & 1 & 3.19 \\
LAMOSA & 3 & 3.46 & SIMEC & 3 & 3.18 \\
MINSA & 3 & 3.43 & KIMBERLY & 3 & 3.14 \\
CEMEX & 3 & 3.42 & GRUMA & 3 & 3.07 \\
COCACOLA & 3 & 3.42 & COLLADO & 3 & 3.01 \\
TENARIS & 3 & 3.39 & ELEMENT & 3 & 2.94 \\
HERDEZ & 1 & 3.36 & AC & 1 & 2.92 \\
CERAMIC & 1 & 3.36 & VASCONI & 1 & 2.75 \\
CH & 3 & 3.35 & VITRO & 3 & 2.71 \\
AHMSA & 3 & 3.34 & PAPPEL & 1 & 1.69 \\
NEMAK & 1 & 3.3 & CULTIBA & 1 & 1.66 \\
\hline
\end{tabular}

Information in Table 2 shows that:

- Manufacturing companies present fractal behavior in the CS system.

- The dynamic of the CS system, explains $80 \%$ with four variables.

- Comparing their $\boldsymbol{\tau}$, companies can be divided into two groups, those with $\tau=1$ and those with $\tau=3$.

\section{Conclusion}

There are different processes that cannot be analyzed by a linear approach, by considering the fractal concept, a new panorama is opened for the study of the dynamic behavior of systems. In this article, the CS variable was analyzed, and it was demonstrated by fractal geometry; which manufacturing companies use to maintain similarity in their production processes. With the aforementioned approach, companies can be seen as dynamic entities that change with time in a systematic way, maintaining increasing and decreasing scales, representing figures in showy occasions such as; dust of Cantor, butterfly wings, snowflakes, and The Sierpinski triangle, among others, but more importantly, the idea is to obtain a methodology that allows for systematic analysis of the operation of organizations. Our numerical experiments, with a non-linear approach, show great promise potential for future applications in this area of the manufacturing industry.

\section{Acknowledgements}

The first author would like to thank the Tecnológico Nacional de México/Instituto Tecnológico de Orizaba; CONACyT_Beca-DEPI; CONACyT_for a Mobility scholarship, Centro de Ciencias de la Atmósfera, UNAM, for its support and sponsorship, for permitting short stays and making possible, the conclusion of this article. Infinite thanks, to the institutions and collaborators, who contributed to the realization of this research, especially to Dr. Tomás Morales Acoltzi, for his time and dedication, acting as a mentor for the fractal theme. Professors Ángel Machorro Rodríguez, Marcos Salazar Medina and Edna Araceli Romero Flores, thank the Coordination of Scientific Research, Academic Secretariat, Technical Secretariat of Academic Exchange and the National Technological Institute of Mexico/Technological Institute of Orizaba for their support, as Visiting Professors to the Center for Atmospheric Sciences, UNAM. 


\section{References}

Barnsley, M.F. (1988). Fractals everywhere. Boston: Academic Press.

De la Rosa -Orea, Guillermo, Mendel-Rojas, Alfonso, Morales - Acoltzi, Tomás, Martínez, Ramírez Enrique, López-Oglesby, Juan Manuel, \& González-Pérez, Manuel. (2014). Caracterización fractal de angioresonancia magnética cerebral. Research in computing science, 21-30.

Deng, X., Peng, J., \& Huang, H. (2009). Research on the fractal company modeling based on competence (pp. 2136-2140). IEEE. http://doi.org/10.1109/ICIEEM.2009.5344226

Gálvez, M.E., Balankin, A., \& Resenos, E. (2009). Enfoque Fractal aplicado en la administración, (104), 45-56.

Grupo BMV, \& Empresas Listadas. (s/f). Recuperado el 10 de abril de 2016. Retrieved from http://www.bmv.com.mx/es/empresas-listadas

Kononov, E. (1996). Visual Recurrence Analysis.

Mandelbrot, B.B. (1982). The fractal geometry of nature. San Francisco: W.H. Freeman.

O.A. Khachay, A.Yu. Khachay, \& O.Yu. Khachay. (2012). Dynamical Model for Evolution of Rock Massive State as a Response on a Changing of Stress-Deformed State. INTECH Open Access Publisher.

Peralta, M.E., Marcos, M., Aguayo, F., Lama, J.R., \& Córdoba, A. (2015). Sustainable Fractal Manufacturing: A New Approach to Sustainability in Machining Processes. Procedia Engineering, 132, 926-933. http://doi.org/10.1016/j.proeng.2015.12.579

Ryu, K., Moon, I., Oh, S., \& Jung, M. (2013). A fractal echelon approach for inventory management in supply chain networks. International Journal of Production Economics, 143(2), 316-326. http://doi.org/10.1016/j.ijpe.2012.01.002

Ryu, K., Son, Y., \& Jung, M. (2003). Modeling and specifications of dynamic agents in fractal manufacturing systems. Computers in Industry, 52(2), 161-182. http://doi.org/10.1016/S0166-3615(03)00099-X

Wang, Y., Luo, Y.-J., \& Peng, Y.-L. (2008). Study the Logistics Financial Management of Supply Chain System Engineering Based on the Fractal Theory (pp. 1-8). IEEE. http://doi.org/10.1109/WiCom.2008.1454

Williams, G.P. (1997). Chaos theory tamed. Washington, D.C: Joseph Henry Press. 